\title{
Microstructure Evolution and Growth Orientation of Directionally Solidified Mg-4 wt\% Zn Alloy with Different Growth Rates
}

\author{
Hong-Min Jia ${ }^{1,2} \cdot$ Xiao-Hui Feng ${ }^{1} \cdot$ Yuan-Sheng Yang ${ }^{1,3}$
}

Received: 30 March 2017/Revised: 24 April 2017/Published online: 2 August 2017

(C) The Chinese Society for Metals and Springer-Verlag GmbH Germany 2017

\begin{abstract}
The microstructure evolution and growth orientation of directionally solidified $\mathrm{Mg}-4 \mathrm{wt} \% \mathrm{Zn}$ alloy in the growth rate range from 20 to $200 \mu \mathrm{m} / \mathrm{s}$ were investigated. A typical cellular structure was observed with a growth rate of $20 \mu \mathrm{m} / \mathrm{s}$, and the cellular spacing was $115 \mu \mathrm{m}$. When the growth rate increased to $60 \mu \mathrm{m} / \mathrm{s}$, cellular structure with some developed perturbations was obtained and the cellular spacing was $145 \mu \mathrm{m}$, suggesting that the cell-to-dendrite transition happened at the growth rate lower than $60 \mu \mathrm{m} / \mathrm{s}$. As the growth rate further increased, the microstructure was dendritic and the primary dendritic arm spacing decreased. The relationship between the primary dendritic arm spacings and the growth rates was in good agreement with Trivedi model during dendritic growth. Besides, X-ray diffraction and transmission electron microscopy analyses showed that the growth direction of directionally solidified $\mathrm{Mg}-4 \mathrm{wt} \% \mathrm{Zn}$ alloy was $\langle 11 \overline{2} 0\rangle$ lay in $\{0002\}$ crystal plane, and the preferred orientation was explained with the lattice vibration model for one-dimensional monatomic chain.
\end{abstract}

KEY WORDS: Directional solidification; Mg-Zn alloy; Microstructure evolution; Primary dendritic arm spacing; Growth orientation

\section{Introduction}

It is well known that microstructure has great effect on the properties of Mg alloys, such as morphology, grain size, distribution of the secondary phases and crystallographic texture [1-8], which are basically determined by solidification process. Usually, directional solidification is used to explore the effects of solidification parameters, namely

Available online at http://link.springer.com/journal/40195

Yuan-Sheng Yang ysyang@imr.ac.cn

1 Institute of Metal Research, Chinese Academy of Sciences, Shenyang 110016, China

2 University of Chinese Academy of Sciences, Beijing 100039, China

3 Shandong Key Laboratory for High Strength Lightweight Metallic Materials, Ji'nan 250014, China temperature gradient and growth rate, on the microstructures that can be independently controlled [6]. Recently, the microstructure evolutions of Mg-based alloys during directional solidification have been investigated widely. For example, Zheng et al. [9] studied the microstructure of directionally solidified AX44 alloy and found that dendritic morphology grew with the growth rate of $15-200 \mu \mathrm{m} / \mathrm{s}$ at the temperature gradient of $4{ }^{\circ} \mathrm{C} / \mathrm{mm}$, and the relationship between primary dendritic arm spacing and cooling rate could be described by Hunt-Lu model. Mirković et al. $[10,11]$ investigated the directional solidification behavior of AZ31 and AM50 alloys and the dendrites with secondary arms were obtained for the two alloys. For directionally solidified $\mathrm{Mg}-\mathrm{Al}$ alloy [12, 13], the cell-todendrite transition was observed and the primary dendritic arm spacing was in agreement with the models of Kurz and Fisher and Trivedi. Lou et al. [14] and Wang et al. [15] found that the microstructures of directionally solidified $\mathrm{Mg}-\mathrm{Gd}$ alloys were typical cellular with different temperature gradients $(20,25$ and $30 \mathrm{~K} / \mathrm{mm})$ at the fixed 
growth rate $(10 \mu \mathrm{m} / \mathrm{s})$ or different growth rates $(10-200 \mu \mathrm{m} / \mathrm{s})$ at the fixed temperature gradient $(30 \mathrm{~K} /$ $\mathrm{mm})$, and the cellular spacings decreased with increasing cooling rates and were in good agreement with Trivedi model. Verissimo et al. [16] studied that the dendritic growth of directionally solidified $\mathrm{Mg}-\mathrm{Zn}$ alloys and observed the equiaxed grains along the entire directionally solidified samples, while dendritic structures with side branches were obtained for directionally solidified $\mathrm{Mg}-\mathrm{Zn}$ alloy as the cooling rate range from 0.05 to $9.00 \mathrm{~K} / \mathrm{s}$ [17]. Due to the different experimental conditions, the comprehensive microstructure evolution of $\mathrm{Mg}-\mathrm{Zn}$ alloy, including cell-to-dendrite transition, is rarely reported. Besides, the relationship between primary dendritic arm spacing and solidification parameter is divergent.

In addition, the preferred growth direction of $\mathrm{Mg}$ alloys is inconsistent. Pettersen et al. [18, 19] indicated that the growth direction of directionally solidified AZ91 alloy was $\langle 11 \overline{2} 0\rangle$ direction at a low temperature gradient and high growth rates, while $\langle 22 \overline{4} 5\rangle$ direction at higher temperature gradients and lower growth rates. Wang et al. [20] studied the growth orientation of $\mathrm{Mg}-\mathrm{Zn}$ alloy with a high $\mathrm{Zn}$ content using X-ray synchrotron tomography, and their results revealed that the dendrites grew along $\langle 11 \overline{2} 0\rangle$ direction, but the solidification condition was different from directional solidification and the high content of $\mathrm{Zn}$ content may affect the result for its high anisotropy. Besides, the analyses of the preferred orientation of $\mathrm{Mg}$ alloys in the previous studies mainly concentrated on their crystallographic characteristics, but other factors, such as heat conduction, were scarcely mentioned.

In this work, directionally solidified $\mathrm{Mg}-4 \mathrm{wt} \% \mathrm{Zn}$ alloy with different growth rates was fabricated and the microstructures were characterized. The relationship between primary dendritic arm spacing $(\lambda)$ and growth rate (v) was established, and the growth orientation of the directionally solidified $\mathrm{Mg}-4 \mathrm{wt} \% \mathrm{Zn}$ alloy was analyzed.

\section{Materials and Methods}

High-purity $\mathrm{Mg}$ (99.99 wt\%) and $\mathrm{Zn} \mathrm{(99.99} \mathrm{wt \% )} \mathrm{were}$ used to prepare $\mathrm{Mg}-4 \mathrm{wt} \% \mathrm{Zn}$ alloy ingots by using an electronic resistance furnace under the protection of $\mathrm{CO}_{2}$ and $0.8 \% \mathrm{SF}_{6}$ mixture gas. Then bars of $120 \mathrm{~mm}$ length and $6.8 \mathrm{~mm}$ diameter for directional solidification were machined from the ingots. During directional solidification experiments, the bar placed in an alumina crucible was melted at $750{ }^{\circ} \mathrm{C}$ and steady for $20 \mathrm{~min}$, and then pulled down at the rates of 20,60, 80, 120, 160 and $200 \mu \mathrm{m} / \mathrm{s}$, respectively, at the temperature gradient of $13 \mathrm{~K} / \mathrm{mm}$ under the protection of argon. The experimental processes have been described at length in our previous studies [21, 22].

The directionally solidified samples cut longitudinally and transversely for microstructure observation were ground, polished and etched with $1 \mathrm{wt} \%$ oxalic acid solution. The primary dendritic arm spacings were measured based on the line intercept method from optical micrographs with ImageJ software. Data were taken at least 10 different regions for each sample and then averaged.

The growth direction of directionally solidified $\mathrm{Mg}-$ $4 \mathrm{wt} \% \mathrm{Zn}$ was examined by X-ray diffraction (XRD) and transmission electron microscopy (TEM). The samples analyzed by XRD were parallel to the growth direction, and the standard thin foils for TEM investigation were prepared perpendicular to the growth direction.

\section{Results}

\subsection{Directional Solidification Microstructures}

The microstructures of the longitudinal and transversal sections of the directionally solidified $\mathrm{Mg}-4 \mathrm{wt} \% \mathrm{Zn}$ alloy with different growth rates are shown in Fig. 1. A typical cellular structure was obtained with the growth rate of $20 \mu \mathrm{m} / \mathrm{s}$ as shown in Fig. 1a, and the polygonal grains could be observed on the transversal sections of the directionally solidified alloy (Fig. 1b). When the growth rate was increased to $60 \mu \mathrm{m} / \mathrm{s}$, the interface was unstable and the cell-to-dendrite transition occurred as result, as shown in Fig. 1c. Further increasing the growth rate up to $120 \mu \mathrm{m} / \mathrm{s}$, a dendritic morphology with side branches was observed. With the increase in growth rate, dendritic structure became finer, as shown in Fig. 1g. For dendritic growth, the shapes of the grains on the transversal sections were same but the width and length varied to some extent as the growth rates increased according to Fig. 1d, f, h.

\subsection{Growth Rates and Primary Dendritic Arm Spacing}

The primary dendritic arm spacings of the directionally solidified $\mathrm{Mg}-4 \mathrm{wt} \% \mathrm{Zn}$ alloy were measured, as shown in Fig. 2. It can be seen that the primary dendritic arm spacings $(\lambda)$ increased as the growth rate $(v)$ increased from 20 to $60 \mu \mathrm{m} / \mathrm{s}$ for the cell-to-dendrite transition, and then decreased with the increase in growth rates for the dendritic growth. The relationship between $\lambda$ and $v$ for samples with dendritic structure at the growth rates of $60-200 \mu \mathrm{m} / \mathrm{s}$ was established as

$\lambda=505.69 v^{-0.283}$. 


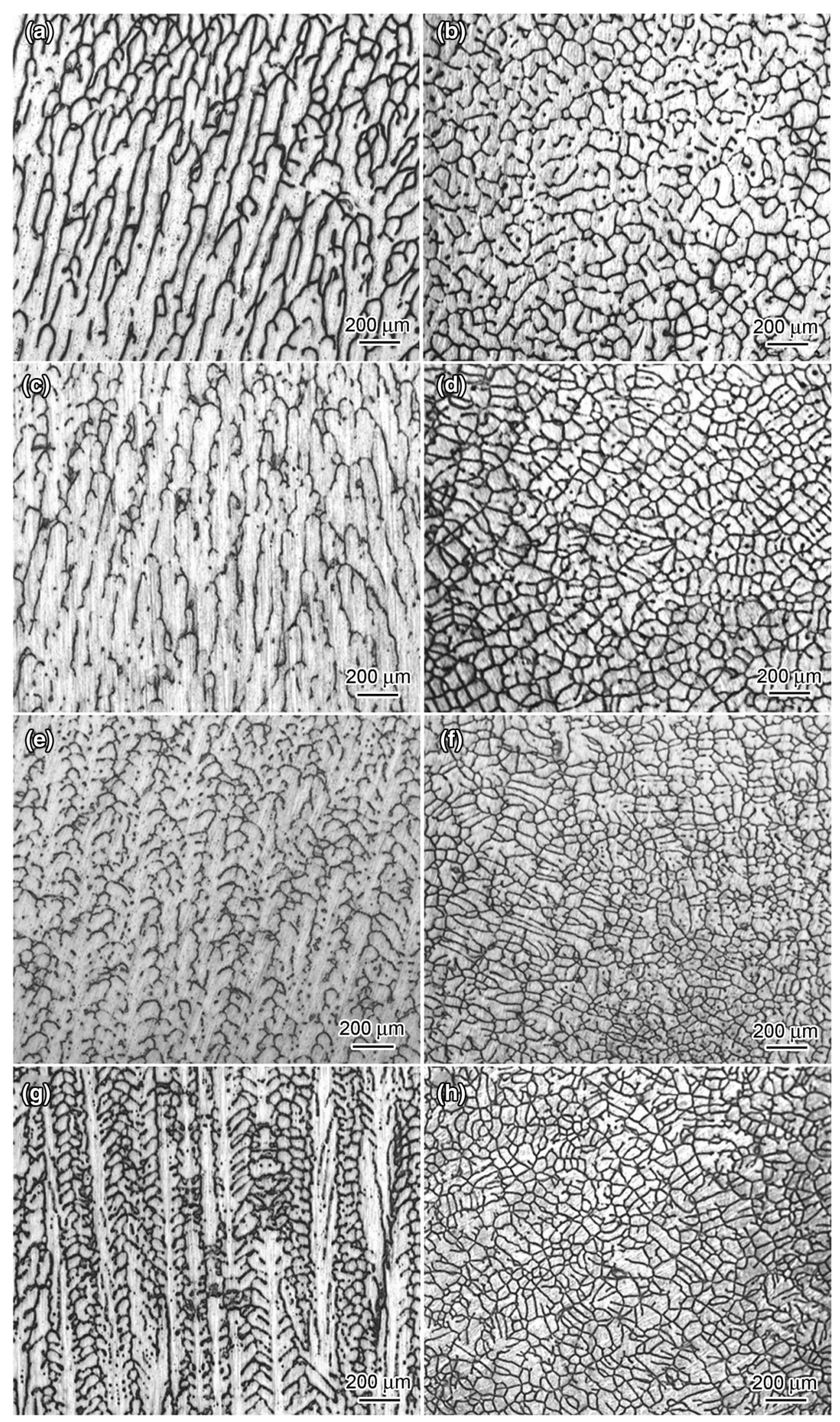

Fig. 1 Microstructures of the directionally solidified Mg-4 wt $\% \mathrm{Zn}$ alloy with different growth rates of $\mathbf{a}, \mathbf{b} v=20 \mu \mathrm{m} / \mathrm{s}, \mathbf{c}, \mathbf{d} v=60 \mu \mathrm{m} / \mathrm{s}, \mathbf{e}$, f $v=120 \mu \mathrm{m} / \mathrm{s}, \mathbf{g}, \mathbf{h} v=160 \mu \mathrm{m} / \mathrm{s}$ 


\subsection{Growth Orientation of the Directionally Solidified Mg-4 wt\% Zn Alloy}

The $\{0002\},\{10 \overline{1} 0\}$ and $\{10 \overline{1} 1\}$ pole figures of the directionally solidified $\mathrm{Mg}-4 \mathrm{wt} \% \mathrm{Zn}$ alloy with different growth rates are shown in Fig. 3. There was a strong peak with non-centro-symmetric discoloration in all the pole figures. The pole figures of $\{0002\}$ crystal plane exhibited a strong basal texture with the maximum intensity of 33.68 , 14.92 and 23.67 under the different three growth rates, respectively. However, the fairly scattered orientation distributions were observed in the pole figures of $\{10 \overline{1} 0\}$ and $\{10 \overline{1} 1\}$ crystal planes.

TEM diffraction pattern from foils taken from the transversal section of the directionally solidified $\mathrm{Mg}-$ $4 \mathrm{wt} \% \mathrm{Zn}$ alloy is shown in Fig. 4. The pattern was obtained with the electron beam parallel to the growth direction. The indexing of the pattern showed the $\langle 11 \overline{2} 0\rangle$ zone axis and the deviation angle from the foil mounting to the $\langle 11 \overline{2} 0\rangle$ zone axis was less than $6^{\circ}$, which demonstrates that the dendritic stems mainly grow along $\langle 11 \overline{2} 0\rangle$ direction. The results were verified by several repeated tests for the alloy with all the tested growth rates. Based on XRD and TEM results, it can be concluded that the growth direction of the directionally solidified $\mathrm{Mg}-4 \mathrm{wt} \% \mathrm{Zn}$ alloy is $\langle 11 \overline{2} 0\rangle$ direction lay in $\{0002\}$ crystal plane, which is not affected by the growth rate in the range of $20-200 \mu \mathrm{m} / \mathrm{s}$.

\section{Discussion}

\subsection{Microstructure Evolution}

Based on the solidification theory, the constitutional undercooling will form in front of solid/liquid interface due to the solute redistribution. The tips of solid/liquid interface can readily reject solute, while the depressed parts of the interface accumulate solute and grow much more slowly. Because the initial perturbations at a small growth rate are too small to further grow, the cellular structure can grow stably, which is consistent with the result of Fig. 1a.

As the growth rate increases, the approximately paraboloidal interface of the cell tips becomes unstable for larger constitutional undercooling. The protuberance will promote into the liquid and break down the plane interface, and thus dendrites will form instead of the cells. Kurz and Fisher [23] developed a criterion for the morphological transition from cell to dendrite, which can be expressed as

$v_{\text {tr }}=G D /\left(\Delta T_{0} k\right)=G D /\left[m C_{0}(k-1)\right]$,

where $v_{\text {tr }}$ is the critical growth rate, $G$ is the temperature gradient, $D$ is the diffusion coefficient in the liquid, $\Delta T_{0}$ is

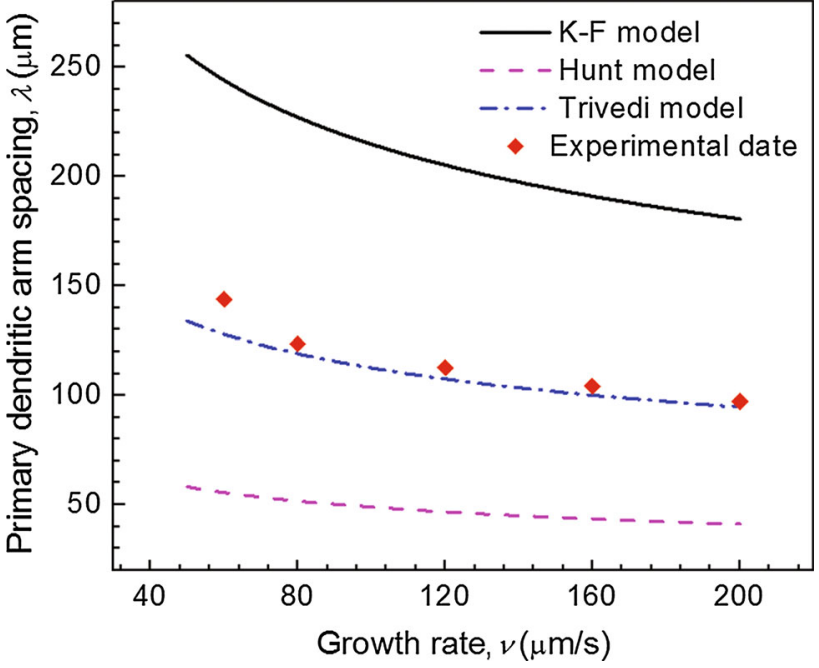

Fig. 2 Variation of primary dendritic arm spacing $(\lambda)$ as a function of growth rate $(v)$

the temperature interval between the liquidus and the solidus, $m$ is the liquidus slope, $k$ is the equilibrium partition coefficient and $C_{0}$ is the initial alloy composition. For $\mathrm{Mg}-4 \mathrm{wt} \% \mathrm{Zn}$ alloy, the value of $v_{\text {tr }}$ is $50.1 \mu \mathrm{m} / \mathrm{s}$, which was calculated according to Eq. (2). The thermophysical parameters of the Mg-4 wt\% $\mathrm{Zn}$ alloy were referred in Refs. [24, 25], $k$ is $0.12, m$ is $-6.04 \mathrm{~K} / \mathrm{wt} \%$ and $D$ is $8.2 \times 10^{-8} \mathrm{~m}^{2} / \mathrm{s}$. As shown in Fig. 1c, the microstructure of $\mathrm{Mg}-4 \mathrm{wt} \% \mathrm{Zn}$ alloy was cellular with some developed perturbations at the growth rate of $60 \mu \mathrm{m} / \mathrm{s}$ and the arm spacing was $145 \mu \mathrm{m}$, which was larger than the cellular spacing at the growth rate of $20 \mu \mathrm{m} / \mathrm{s}$, suggesting that the cell-to-dendrite transition happened at the growth rate lower than $60 \mu \mathrm{m} / \mathrm{s}$. The experimental result is in good agreement with the theoretical calculation.

As the growth rate further increases, the rejected solute from the solid cannot fully diffuse out and will be accumulated at the interdendritic region. The solute concentration gradient and the constitutional undercooling of the interdendritic melt are larger so that the interdendritic solid/liquid interface is unstable and the protrusion forms. The solute at the protrusion tip diffuses quickly, and thus the protrusion can grow continually to become a new primary dendritic and the primary dendritic arm spacing decreases as shown in Fig. 1e, g. Based on the above analyses, the microstructure evolution mainly depends on the constitutional undercooling and the interface stability.

\subsection{Effect of Growth Rate (v) on the Primary Dendritic Arm Spacing $(\lambda)$}

The primary dendritic arm spacing is related to the material characteristics and solidification conditions. Different theoretical models have been proposed to predict the primary 

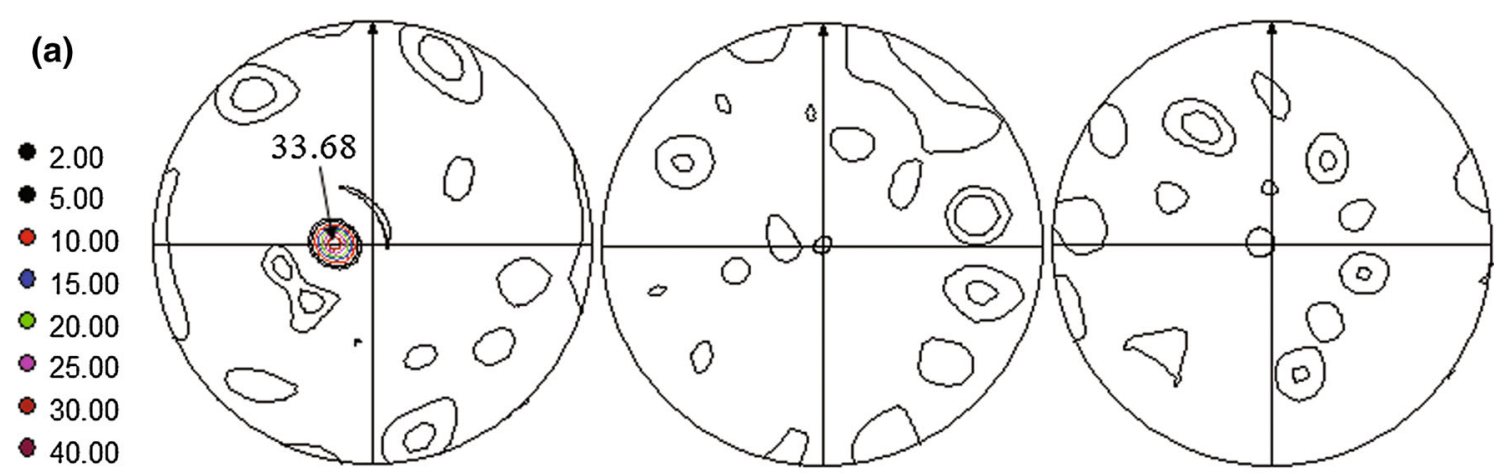

(b)

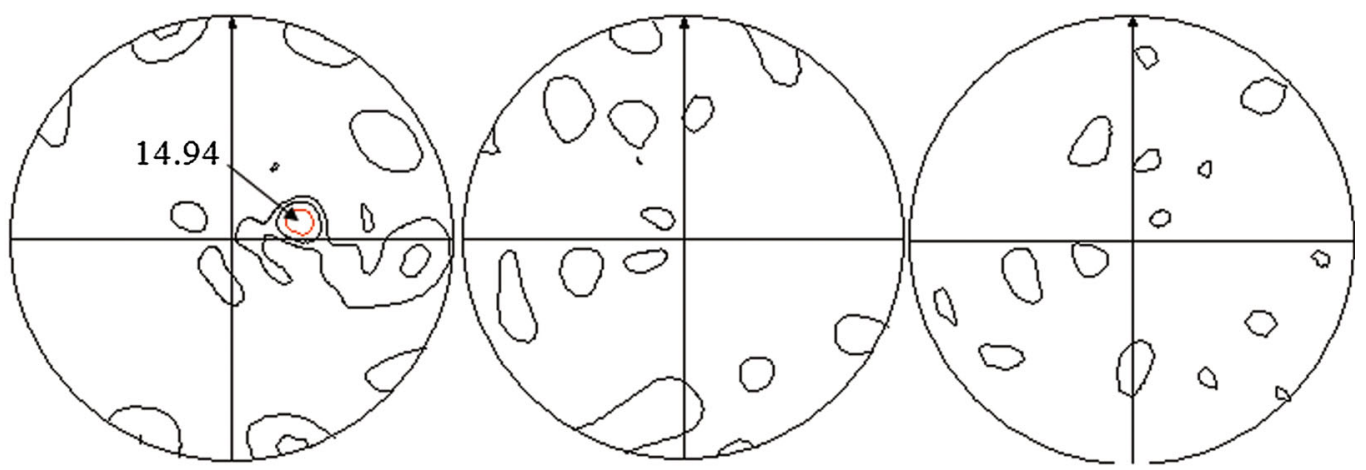

(c)

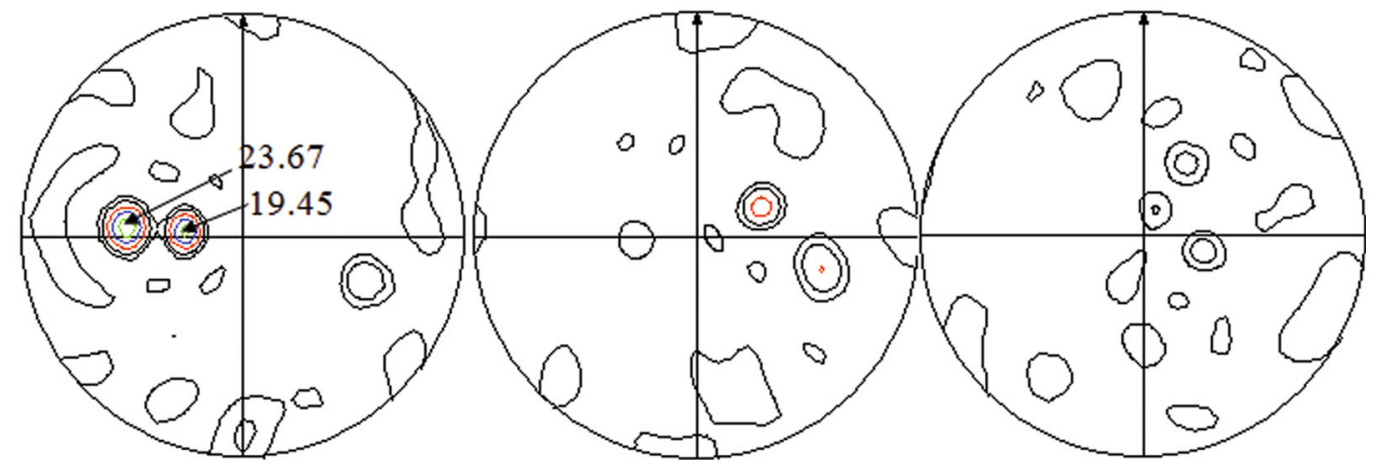

Fig. $3\{0002\},\{10 \overline{1} 0\}$ and $\{10 \overline{1} 1\}$ pole figures of the directionally solidified $\mathrm{Mg}-4 \mathrm{wt} \% \mathrm{Zn}$ alloy with the growth rates a $v=20 \mu \mathrm{m} / \mathrm{s}$, b $v=60 \mu \mathrm{m} / \mathrm{s}, \mathbf{c} v=120 \mu \mathrm{m} / \mathrm{s}$

dendritic arm spacing, such as Hunt model [25], Kurz and Fisher model [23] and Trivedi model [26]. The measured values of $\lambda$ and the calculated ones by the above theoretical models for the directionally solidified $\mathrm{Mg}-4 \mathrm{wt} \% \mathrm{Zn}$ alloy are shown in Fig. 5. The calculated values by Kurz-Fisher model and Hunt model obviously deviate from the measured ones, while the measured results are in a good agreement with Trivedi model. The main difference of the three models is that for Trivedi model [26], the $L$ parameter is introduced as shown in Eq. (3), which is related to interface energy (Eq. 4) and can be expressed as Eq. (5):

$\lambda=2.83[m(k-1) D \Gamma L]^{0.25} C_{0}^{0.25} v^{-0.25} G^{-0.5}$,

$e=\left(2 \sigma / \Delta S R^{2}\right) L$,

$L=(l+1)(l+2) / 2$, where $e$ is the effect of interface energy, $\sigma$ is the interface energy, $\Gamma$ is Gibbs-Thomson coefficient, $\Delta S$ is the entropy change, $R$ is the radius of curvature and $l$ is the harmonic number, which dominates the dendritic growth. Whether the perturbation formed on the interface grows or shrinks partly depends on interface energy, especially for the dendrites [6]. Therefore, Trivedi model exhibits good agreement with the experimental results in the growth rate range of $60-200 \mu \mathrm{m} / \mathrm{s}$.

\subsection{Analysis of the Preferred Orientation}

As shown in Figs. 3 and 4, the growth direction of directionally solidified $\mathrm{Mg}-4 \mathrm{wt} \% \mathrm{Zn}$ alloy is $\langle 11 \overline{2} 0\rangle$ lay in $\{0002\}$ crystal plane. The $\{0002\}$ crystal plane of the tested alloy that has hexagonal close packed (hcp) structure 


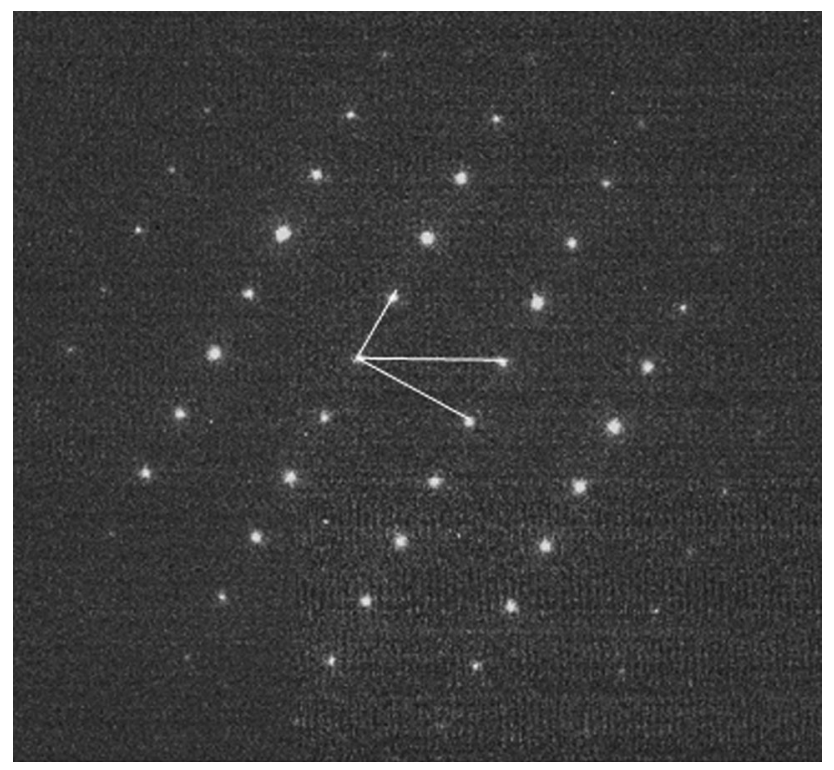

Fig. 4 TEM diffraction pattern of the directionally solidified $\mathrm{Mg}-$ $4 \mathrm{wt} \% \mathrm{Zn}$ alloy with all the tested growth rates

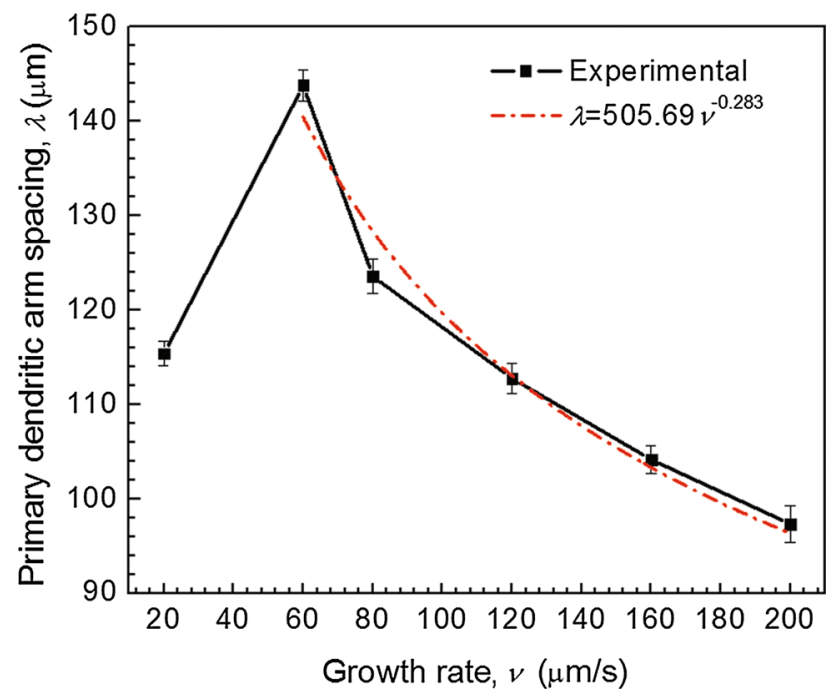

Fig. 5 Comparison of the measured values of $\lambda$ and the calculated ones by theoretical models for the directionally solidified $\mathrm{Mg}-4 \mathrm{wt} \%$ Zn alloy

is the closest packed, which has the lowest energy and the strongest atomic bonds [27]. Hence, the dendrites grow preferentially in $\langle 11 \overline{2} 0\rangle$ direction for the low surface stiffness.

Wang et al. [28] pointed out that the growth direction of columnar dendrites would rotate to the direction of the thermal gradient gradually as the cooling rate increases. As the growth rate increases, the thermal release will dominate the solidification and the heat flow mainly depends on the temperature gradient during the directional solidification process. For a cell with hep structure, there are two atoms that have equal quality and the basically coincidence of mass center. The heat transfer process of the sample can be explained with the lattice vibration model for one-dimensional monatomic chain [29]. The dispersion relation is shown as Eq. (6).

$\omega=2(\beta / m)^{1 / 2} \sin (a q / 2)$,

where $\omega$ is frequency, $\beta$ is the restoring force coefficient, $m$ is atomic mass, $a$ is the atomic spacing of the adjacent two atoms and $q$ is the wave vector. Based on the Boltzmann statistical law [28] and lattice dynamic theory [30], the relationship between temperature gradient and atomic spacing can be described as follows:

$$
\begin{aligned}
\partial T / \partial a= & \left(n h / k_{\mathrm{B}}\right)\{A /[(B+1)(B \\
& +2)]\}^{1 / 2} a^{-(B+2) / 2} q \cos (a q / 2),
\end{aligned}
$$

where $T$ is the temperature, $A$ is constant, $B$ is the Born number, $n$ is the phonon number, $k_{B}$ is Boltzmann constant and $h$ is the Plank constant. In the hep structure, $\langle 11 \overline{2} 0\rangle$ direction is closest packed and has the smallest atomic spacing [25]. Thus, the minimum value of $a$ along $\langle 11 \overline{2} 0\rangle$ direction results in the maximum temperature gradient. Besides, the smallest atomic density between two adjacent cells along $\langle 11 \overline{2} 0\rangle$ direction leads to the least resistance of heat conduction. Thus, $\langle 11 \overline{2} 0\rangle$ direction is beneficial to heat conduction and crystal growth.

\section{Conclusions}

Microstructure evolution and growth direction of the directionally solidified $\mathrm{Mg}-4 \mathrm{wt} \% \mathrm{Zn}$ alloy in the growth rate range of $20-200 \mu \mathrm{m} / \mathrm{s}$ at a temperature gradient of $13 \mathrm{~K} / \mathrm{mm}$ were investigated. Conclusions can be drawn as follows:

1. The microstructure was typical cellular structure at the growth rate of $20 \mu \mathrm{m} / \mathrm{s}$. The cell-to-dendrite transition occurred at the growth rate lower than $60 \mu \mathrm{m} / \mathrm{s}$, and with the increase in the growth rate, dendritic structure with side branches was obtained.

2. The primary dendritic arm spacing decreased with the increase in the growth rate for sample with dendritic structure, and the relationship between $\lambda$ and $v$ was established as: $\lambda=505.69 v^{-0.283}$ for the $\mathrm{Mg}-4 \mathrm{wt} \%$ $\mathrm{Zn}$ alloy, which is in good agreement with Trivedi model.

3. The growth direction of the directionally solidified $\mathrm{Mg}-4 \mathrm{wt} \% \mathrm{Zn}$ alloy is $\langle 11 \overline{2} 0\rangle$ direction lay in $\{0002\}$ crystal plane, which is not affected by growth rates in the range of $20-200 \mu \mathrm{m} / \mathrm{s}$. 


\section{References}

[1] B.L. Mordike, T. Ebert, Mater. Sci. Eng. A 302, 37 (2001)

[2] M. Günaüz, E. Cadirli, Mater. Sci. Eng. A 327, 167 (2002)

[3] J. Luo, H. Yan, N. Zheng, R.S. Chen, Acta Metall. Sin. (Engl. Lett.) 29, 205 (2016)

[4] I.J. Polmear, Mater. Sci. Technol. 10, 1 (1994)

[5] S. Shao, Y. Liu, C.S. Xu, Y.X. Xu, B. Wu, X.S. Zeng, X.F. Lu, X.J. Yang, Acta Metall. Sin. (Engl. Lett.) 28, 7 (2015)

[6] H.Z. Fu, J.J. Guo, L. Liu, Directional solidification and processing of advanced materials (Science Press, Beijing, 2008), pp. 237-251

[7] D.H. Hou, S.M. Liang, R.S. Chen, C. Dong, E.H. Han, Acta Metall. Sin. (Engl. Lett.) 28, 115 (2015)

[8] Q.S. Yang, Z.J. Yu, H.C. Pan, Q.W. Dai, J.H. Li, Acta Metall. Sin. (Engl. Lett.) 29, 475 (2016)

[9] X.W. Zheng, A.A. Luo, C. Zhang, J. Dong, R.A. Waldo, Metall. Mater. Trans. A 43, 3239 (2012)

[10] D. Mirković, R. Schmid-Fetzer, Metall. Mater. Trans. A 40, 958 (2009)

[11] D. Mirković, R. Schmid-Fetzer, Metall. Mater. Trans. A 40, 974 (2009)

[12] C. Zhang, D. Ma, K.S. Wu, H.B. Cao, G.P. Cao, Intermetallics 15, 1395 (2007)

[13] M. Paliwal, I.-H. Jung, Acta Mater. 61, 4848 (2016)
[14] S.F. Luo, G.Y. Yang, S.J. Liu, J.H. Wang, J.H. Li, W.Q. Jie, Mater. Sci. Eng. A 662, 214 (2016)

[15] J.H. Wang, G.Y. Yang, S.J. Liu, W.Q. Jie, Trans. Nonferrous Metals Soc. China 26, 1294 (2016)

[16] N.C. Verissimo, C. Brito, W.L.R. Santos, N. Cheung, J.E. Spinelli, A. Garcia, J. Alloys Compd. 662, 1 (2016)

[17] M. Paliwal, I.-H. Jung, J. Cryst. Growth 394, 28 (2014)

[18] K. Pettersen, N. Ryum, Metall. Trans. A 20, 847 (1989)

[19] K. Pettersen, O. Lohen, N. Ryum, Metall. Trans. A 21, 221 (1990)

[20] M.Y. Wang, Y.J. Xu, T. Jing, Scr. Mater. 67, 629 (2012)

[21] H.M. Jia, X.H. Feng, Y.S. Yang, Mater. Sci. Forum 816, 411 (2015)

[22] H.M. Jia, X.H. Feng, Y.S. Yang, Corros. Sci. 120, 75 (2017)

[23] W. Kurz, D.J. Fisher, Acta Mater. 29, 11 (1981)

[24] S. Wang, D. Liu, Y. Du, L. Zhang, Q. Chen, A. Engström, Int. J. Mater. Res. 104, 721 (2013)

[25] J.D. Hunt, S.Z. Lu, Metall. Mater. Trans. A 27, 611 (1996)

[26] R. Trivedi, Metall. Mater. Trans. A 15, 9772 (1984)

[27] Y. Luo, R. Qin, Surf. Sci. 630, 195 (2014)

[28] Y.B. Wang, L.M. Peng, Y.Z. Ji, X.X. Cheng, N. Wang, Y. Zhao, Y.N. Fu, L.Q. Chen, W.J. Ding, Mater. Lett. 163, 218 (2016)

[29] P. Dean, Rev. Mod. Phys. 44, 127 (1972)

[30] M. Born, K. Huang, Dynamical theory of crystal lattices (Oxford University Press, Oxford, 1954), pp. 28-30 